\title{
Development of a Simplified Version and Test-Retest Reliability for Korean Tinnitus Primary Function Questionnaire
}

\author{
Sohee Heo' ${ }^{1}$ In-Ki Jin² \\ 'Department of Speech Pathology and Audiology, Graduate School, Hallym University, Chuncheon, Korea \\ ${ }^{2}$ Division of Speech Pathology and Audiology, Research Institute of Audiology and Speech Pathology, \\ College of Natural Sciences, Hallym University, Chuncheon, Korea
}

한국어 이명주요기능설문지의 검사-재검사 신뢰도 검증 및 간소화 버전 제안

허 소 희 ${ }^{1} \cdot$ 진 인 기 ${ }^{2}$

한림대학교 일반대학원 언어병리청각학과', 한림대학교 자연과학대학 언어청각학부 · 청각언어연구소 ${ }^{2}$

\begin{abstract}
Purpose: The purpose of this study is to verify the test-retest reliability of the Korean version of the tinnitus primary function questionnaire (K-TPFQ) and to propose a simplified version of the K-TPFQ. Methods: In the test-retest reliability measure of the K-TPFQ, 31 participants were asked to complete the K-TPFQ on two occasions. Correlation between the results of the two questionnaires was confirmed by Pearson correlation coefficient. Then, a total of 110 subjects participated in the proposed, simplified version. Following factor analysis of the K-TPFQ, three items with high factor loadings for each subscale were selected as simplified version items. Internal consistency and validity were analyzed for the 12 items of the simplified version of the K-TPFQ. Results: The results of the test-retest reliability analysis of K-TPFQ showed significantly high correlations in all items, subscales, and total scores $(r=0.598-0.927)$. As a result of factor analysis, all items in each subscale showed high communalities. Therefore, we extracted 3 items with high content validity and high factor loadings from each subscale and adopted a total of 12 items for the simplified version. The results of the internal consistency test of the simplified version showed good validity and significantly high internal consistency of all items and subscales $(\alpha=0.839-0.950)$. Conclusion: This study verified the high reliability and validity of the K-TPFQ. Therefore, it can be used to effectively evaluate the secondary effects of tinnitus in domestic clinics. In addition, the simplified version will reduce the time for evaluating tinnitus sufferers.
\end{abstract}

Key Words: Tinnitus, Tinnitus primary function questionnaire, Questionnaire, Reliability, Factor analysis.

Received: July 22, 2019 / Revised: August 30, 2019 / Accepted: September 9, 2019

Correspondence: In-Ki Jin, Division of Speech Pathology and Audiology, Research Institute of Audiology and Speech Pathology, College of Natural Sciences, Hallym University, 1 Hallymdaehak-gil, Chuncheon 24252, Korea

Tel: +82-33-248-2221 / Fax: +82-33-256-3420 / E-mail: inkijin@hallym.ac.kr

\section{INTRODUCTION}

이명(tinnitus)은 외부에서 주어지는 소리 자극이 없음에도 불구하고 소리를 인지하는 현상을 말한다(Jastreboff, 1990). 이 명을 분류할 수 있는 방법은 다양하지만, 치료적 접근법 유무 에 따라 두 가지로 분류하자면 발생 기전을 명확하게 알 수 있

(cc) This is an Open Access article distributed under the terms of the Creative Commons Attribution Non-Commercial License (https://creativecommons.org/licenses/by-nc/4.0) which permits unrestricted non-commercial use, distribution, and reproduction in any medium, provided the original work is properly cited.
는 객관적 이명과 발생 기전을 확인하기 어려운 주관적 이명으 로 나눌 수 있다(Lanting et al., 2009). 객관적 이명의 대표적인 예시로는 청각 기관 근처의 혈관 이상 등의 문제로 발생하는 박 동성 이명이 있다. 이러한 경우 원인을 파악하여 이과적 처치나 약물 치료 등의 치료적 접근법을 적용할 수 있으며, 그 원인을 적절히 치료하면 이명이 소실되기도 한다(Nam \& Ryu, 2018). 그러나 주관적인 이명의 경우 기전을 알 수 없기 때문에 직접적 인 치료가 어려워 증상을 호전시킬 수 있는 상담 및 소리 치료 등의 다양한 재활법들이 제안되고 있다(Henry et al., 2006; 
Jastreboff \& Jastreboff, 2000; Reavis et al., 2012). 이명을 겪 는 대상자들은 이명으로 인한 삶의 질에 영향을 주는 고통을 호소하기도 하는데 대표적인 증상으로 수면 방해, 집중력 혹은 의사소통 능력 저하, 불안 등이 있으며 심한 경우 우울증이나 자살 충동으로 이어지기도 한다(Heller, 2003; Malouff et al., 2011). 주관적 이명을 평가하는 방법은 대표적으로 심리음향학 적 평가인 이명도검사(tinnitogram)와 심리학적 평가인 자가 보고 설문지가 있다(Choi, 2012). McFadden(1982)은 표준화된 이명 검사가 없다는 문제를 인식하고 총 4가지의 검사로 이루어 진 이명도검사를 개발하였으며, 이 방식이 현재까지도 임상에 서 주로 측정되고 있다. 이명도검사는 음조검사(pitch matching), 음량검사(loudness matching), 최소차폐강도(minimum masking level), 잔여억제(residual inhibition)로 구성된다(McFadden, 1982). 자가 보고 설문지를 통하여 이명에 대한 반응 을 측정하는 경우, 이명을 겪고 있는 대상자의 관점에서 이명이 삶에 미치는 영향을 파악할 수 있다는 장점이 있다. 또한 주관 적으로 인지하는 이명의 영향을 수치화할 수 있기 때문에 재활 전후의 점수 변화를 통하여 재활의 효과를 확인할 수 있어 임 상뿐만 아니라 연구 환경에서도 유용하게 사용할 수 있고 적은 비용으로 검사를 진행할 수 있는 이점이 있다(Lee et al., 2018).

현재 개발된 이명 설문지는 10 개 이상으로 다양하고, 주로 영어로 개발되어 사용하고 있으나 비영어권 국가에서도 모국어 로 번역하고 검증 과정을 거쳐 사용하고 있다(Meikle et al., 2012). 그중 이명장애지수(tinnitus handicap index, THI)와 이 명장애설문지(tinnitus handicap questionnaire, THQ)가 한국 어 번역 및 검증 과정을 거쳐 국내 임상에서 사용되고 있다(Jun et al., 2015; Kim et al., 2002; Kuk et al., 1990; Newman et al., 1996).

최근 Tyler et al.(2014)은 이명주요기능설문지(tinnitus primary function questionnaire, TPFQ)를 개발하였다. TPFQ는 세계보건기구(World Health Organization)가 발표한 국제기능 장애건강분류(International Classification of Functioning, Disability and Health) 모델을 기반으로 개발되었다. 국제기능 장애건강분류 모델은 개인의 건강 상태가 신체적 혹은 심리적 인 손상에만 국한되는 것이 아니라, 사회활동이나 일상생활을 포함한 전반적인 삶에도 이차적 영향을 미친다는 모델이다 (World Health Organization, 2001). Tyler et al.(2014)은 이러 한 모델에 이명을 대입시켜 모델화하였다. 이 모델의 핵심은 이 명이 발생하게 되면 감정, 듣기 능력, 수면, 집중력 등 주요 기능 (primary function)에 일차적 영향을 일으키게 되고, 이는 각종 활동에 제약을 만들어 사회적인 활동이나 업무 등 2차적 활동 (secondary activities)에 이차적 영향을 미치게 된다는 것이다. 따라서 Tyler et al.(2014)은 이차적 영향으로 이어지는 대표적
인 일차적 영향 4 가지를 하위척도로 설정하여 주관적인 이명 을 측정할 수 있는 $\mathrm{TPFQ}$ 를 개발하고 검증하였다. $\mathrm{TPFQ}$ 는 각 문항당 100 점 만점으로 각 하위척도마다 5 개의 문항이 있어 총 20 개의 문항으로 구성되어 있으며, 점수가 높을수록 이명의 정 도가 심한 것으로 평가한다. 모든 문항의 점수를 평균으로 계산 하여 전체 점수를 100점 만점으로 나타내며, 각 하위척도마다의 평균 점수를 구할 수도 있다. 이를 통해 이명이 감정, 듣기 능력, 수면, 집중력 등에 미치는 영향을 나누어 평가할 수 있다. 따라 서 $\mathrm{TPFQ}$ 는 각 하위척도의 결과를 바탕으로 더 구체적인 재활 계획을 수립할 수 있으며, 기존에 사용하고 있던 설문지보다 문 항이 적어(THI: 총 25문항, THQ: 총 27문항) 설문지 작성 소요 시간을 단축시킬 수 있다는 장점이 있다(Shin et al., 2019).

Tyler et al.(2014)이 TPFQ를 개발한 것에 이어 Shin et al. (2019)은 TPFQ의 번역 및 일부 검증 과정을 진행하여 국내 도 입을 모색하였다. 설문지 번역 과정은 $\mathrm{TPFQ}$ 의 개발자인 Tyler 교수에게 번역 및 사용에 대한 허락을 받은 후, 청각 설문지 번 역 과정에 따라 이루어졌다(Hall et al., 2018; Harkness et al., 2004). 일반적으로 설문지 검증 과정에서 사용되는 척도는 실행 가능성(feasibility), 신뢰도(reliability), 타당도(validity) 등이 있 다(de Yébenes et al., 2009; Schmidt \& Steindorf, 2006). 실행 가능성은 해당 설문지의 문항 난이도 및 해석의 어려움 정도를 확인하는 과정으로, 응답자들의 반응을 토대로 질문의 간결성 과 정확성, 소요 시간 등을 파악하는 방법으로 이루어진다. 신 뢰도는 설문지의 응답 결과가 일관성 있게 측정되는 정도를 뜻 하며, 통계적 검증 방법으로는 내적 일관성(internal consistency)과 검사-재검사 신뢰도(test-retest reliability) 등이 있다. 타당도는 설문지의 목표 항목을 설문지가 얼마나 정확하게, 혹 은 적합하게 측정하는지 확인하는 척도로써 통계적 검증 방법 으로는 구성 타당도를 확인하는 방법이 있다. 구성 타당도는 주로 요인 분석(factor analysis)과 이미 검증이 완료된 유사한 관점을 평가하는 다른 설문지와의 상관관계 분석을 통한 수렴 타당도 검증 등을 실시한다(de Yébenes et al., 2009). Shin et al.(2019)은 한국어로 번역한 이명주요기능설문지(Korean version of the TPFQ, K-TPFQ)의 실행가능성을 확인하였으며, 신뢰도 검증에서는 내적 일관성 검증을, 타당도 검증에서는 수 렴 타당도 검증을 실시하여 바람직한 수준임을 확인하였다.

이명 설문지는 이명으로 인한 대상자의 어려움 정도 및 삶의 질 변화를 측정할 수 있는 다양한 문항으로 구성되어 있지만 다수의 문항은 작성 시간의 증가로 이어져 임상 적용 시 어려 움이 발생하기도 한다. 따라서 몇몇 설문지는 임상의 여건에 따 라 빠른 시간에 측정 가능한 간소화 버전을 개발하여 제안하 고 있다(Hiller \& Goebel, 2004; Mun et al., 2013; Newman et al., 2008; Tyler et al., 2014). Newman et al.(2008)은 총 25 
문항인 $\mathrm{THI}$ 를 10 문항으로 축약한 버전을 개발하였으며, 항목총계 상관관계(item-total correlation)를 기준으로 최종 10문항 을 선택하였다. Korean version of the THI (K-THI) 또한 항 목-총계 상관계수를 기준으로 최종 10 문항을 간소화 버전으로 제안하였다(Mun et al., 2013). Hiller \& Goebel(2004)은 이명 설 문지(tinnitus questionnaire) 총 52문항을 12문항으로 축약하여 제안하였으며, 항목-총계 상관관계와 검사-재검사 신뢰도를 바탕으로 최종 12 문항을 선택하였다. TPFQ 또한 요인 분석을 통하여 총 20 문항 중에서 12 문항을 추려낸 간소화 버전을 제 안하였다(Tyler et al., 2014).

Shin et al.(2019)이 제안한 K-TPFQ는 일부 검증이 실시되었 지만, 검사-재검사 신뢰도 측정과 요인 분석은 이루어지지 않았 다. 내적 일관성이 검증되었다고 하더라도 이명에 대한 대상자 의 인식 변화 또는 중재와 무관하게 설문지 검사 결과가 일관 성 있게 측정되지 못한다면 검사도구에 대한 응답자의 반응이 안정적이지 않다는 것이기 때문에 안정성 계수(coefficient of stability)가 확보되지 못하여 유용한 설문지로 적용되기에는 한 계가 발생할 수 있다. 따라서 설문지가 일관성 있게 측정되는지 확인할 수 있는 검사-재검사 신뢰도 검증이 이루어진다면 설문 지의 신뢰도를 더욱 높게 확립할 수 있을 것이다. 또한 K-TP$\mathrm{FQ}$ 의 내적 일관성이 매우 높게 측정되었는데(Cronbach's al$\mathrm{pha}=0.95)$, 이 원인이 항목 내 유사 질문의 수가 많아서 내적 일관성 결과에 직접적으로 영향을 끼친 것인지, 아니면 문항 간 내적 일관성이 높게 나타난 것인지 확인할 수 없는 약점이 있다. 이러한 경우 요인 분석을 실시한다면 원인 분석이 가능하 며, 동시에 설문지의 타당성을 높일 수 있다. 요인 분석을 위한 표본의 수는 보통 100 개 이상이 안전하다고 알려져 있으며, 설 문지의 경우 문항 수의 4 5배 이상의 표본 수가 필요하다. 하지 만 선행연구에서 분석한 대상자 수는 총 79명으로 요인 분석을 실시하기에는 한계가 있었다(Shin et al., 2019). 또한 영어 버전 에서는 12 문항으로 간소화한 버전의 신뢰도 검증이 이루어져 바쁜 임상에서 실시할 수 있는 간소화 설문지를 확립하였지만 한국어 버전에서는 간소화 버전 제안 및 신뢰도 검증은 이루어 지지 않았다.

따라서 본 연구의 목적은 $\mathrm{K}-\mathrm{TPFQ}$ 의 신뢰도를 일부 검증한 선행연구(Shin et al., 2019)에서 고려되지 못했던 검사-재검사 신뢰도 측정과 요인 분석을 실시하여 설문지의 신뢰도와 타당도 를 검증함과 더불어 설문지의 작성 소요 시간을 단축할 수 있는 간소화 버전을 제안하는 것이었다. 본 연구를 통하여 K-TPFQ 의 높은 검사-재검사 신뢰도 및 각 하위척도마다 적절한 요인 적재량(factor loading)이 나타난다면 설문지의 검증력을 한층 높일 수 있을 것이다. 또한 선행연구(Tyler et al., 2014)와 마찬 가지로 각 하위척도 내에서 요인 적재량이 높은 일부 문항들을
추출한다면 간소화 버전을 제안할 수 있어 설문지 작성 시간의 여건이 부족한 임상에서 유용하게 사용될 수 있을 것이다.

\section{MATERIALS AND METHODS}

\section{연구 대상}

본 연구에는 검사-재검사 신뢰도 검증을 위해서 이명으로 인해 어려움을 겪고 있는 성인 31명을 대상으로 진행하였다(평 균 연령: 71.2세, 연령 범위: 39 89세). 연구에 참여한 모든 대상 자는 이과적 질환이 없었으며, 어떠한 이명 치료나 재활을 받고 있지 않은 참여자를 대상으로 하였다. 연구 대상자들의 순음청 력검사(pure-tone audiometry; GSI-61, Grason-Stadler Inc., Eden Prairie, MN, USA) 결과는 Figure 1에 제시하였으며, 이 명도검사(tinnitogram) 결과는 Table 1에 제시하였다.

또한 한국어 이명주요기능설문지 간소화 버전 제안을 위한 요인 분석을 실시하기 위하여 선행연구(Shin et al., 2019)에서 수집된 79명의 설문지 검사 결과를 함께 활용하여 총 110 명의 데이터를 활용하였으며, 선행연구의 대상자는 지역 의료기관(소 리귀클리닉)에서 만성 이명으로 진단받은 대상자로 본 연구의 대상자 조건과 일치하였다. 모든 대상자는 1년 이상 이명을 호 소하였으며, 경도에서 중도 정도의 청력역치를 보였다.

모든 대상자들은 연구에 참여하기 전 연구의 목적, 방법 및 절차에 대해 충분한 설명을 제공받았으며, 이에 대한 자발적인 참여 동의서 서명이 이루어진 후 연구에 참여하였다. 연구 참여 가 종료된 후 모든 참여자는 연구 참여에 대한 수고비를 지급 받았다.

\section{연구 절차}

본 연구에 참여한 대상자들은 총 두 번의 K-TPFQ (Shin et

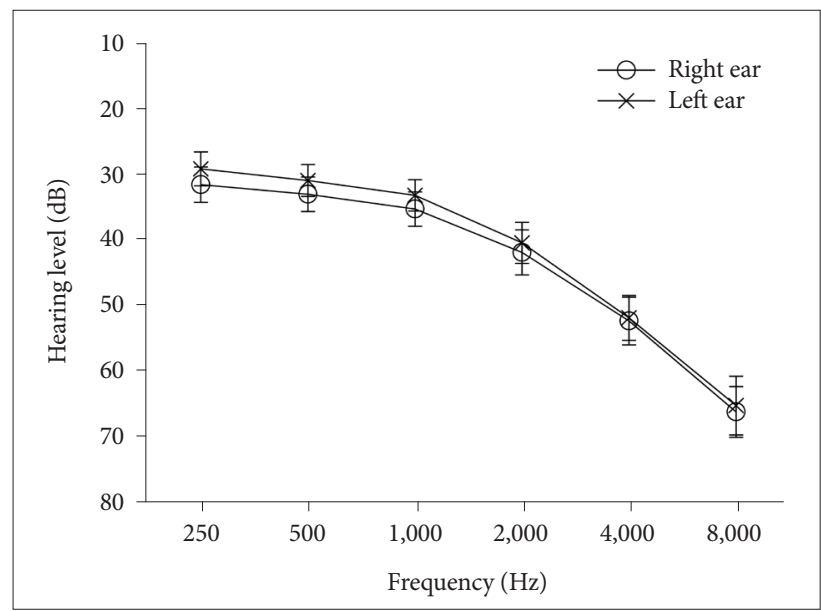

Figure 1. Averaged pure-tone thresholds of the 31 participants between $250 \mathrm{~Hz}$ and $8,000 \mathrm{~Hz}$. 
Table 1. Results of tinnitogram for the 31 participants

\begin{tabular}{|c|c|c|c|}
\hline $\begin{array}{l}\text { Subject } \\
\text { no. }\end{array}$ & $\begin{array}{l}\text { Tinnitus } \\
\text { pitch }(\mathrm{Hz})\end{array}$ & $\begin{array}{c}\text { Tinnitus } \\
\text { loudness (dB SL) }\end{array}$ & $\begin{array}{c}\text { Minimum } \\
\text { masking level (dB SL) }\end{array}$ \\
\hline 1 & 2,000 & 0 & - \\
\hline 2 & 6,000 & 5 & - \\
\hline 3 & 1,000 & 5 & - \\
\hline 4 & 4,000 & 10 & 5 \\
\hline 5 & 3,000 & 5 & - \\
\hline 6 & 8,000 & 0 & - \\
\hline 7 & 2,000 & 20 & 20 \\
\hline 8 & 2,000 & 0 & - \\
\hline 9 & 4,000 & 10 & 10 \\
\hline 10 & 6,000 & 15 & -10 \\
\hline 11 & 4,000 & 5 & - \\
\hline 12 & 4,000 & 5 & - \\
\hline 13 & 4,000 & 5 & - \\
\hline 14 & 500 & 5 & - \\
\hline 15 & 750 & 5 & - \\
\hline 16 & 4,000 & 10 & - \\
\hline 17 & - & - & - \\
\hline 18 & 8,000 & 10 & 25 \\
\hline 19 & 6,000 & 5 & - \\
\hline 20 & 8,000 & 30 & - \\
\hline 21 & 1,500 & 5 & - \\
\hline 22 & 6,000 & 25 & - \\
\hline 23 & 4,000 & 10 & 15 \\
\hline 24 & 4,000 & - & - \\
\hline 25 & 125 & - & - \\
\hline 26 & 4,000 & 10 & 15 \\
\hline 27 & 4,000 & 10 & 5 \\
\hline 28 & 4,000 & 0 & -10 \\
\hline 29 & 8,000 & - & - \\
\hline 30 & 3,000 & 0 & - \\
\hline 31 & 4,000 & 5 & - \\
\hline
\end{tabular}

al., 2019)를 작성하였다. 각 대상자들은 순음청력검사와 이명 도검사를 마친 후 설문지를 직접 작성하도록 지시받았다. 두 번 째 설문지 작성은 첫 번째 설문지 작성일로부터 약 2 3주(평균 기간: 17.4일, 기간 범위: 15 20일) 후에 시행되었다. 설문지의 검사-재검사 신뢰도 측정 시 두 검사 간의 기간이 너무 짧을 경우 학습 효과를 불러올 수 있으며, 반대로 기간이 너무 길 경 우에는 대상자의 상태가 실제로 변화할 수 있어 두 검사 간의 상관관계가 낮게 평가될 우려가 있다. 따라서 일반적으로 설문 지의 검사-재검사 신뢰도를 구하는 연구에서는 두 설문조사의 간격을 2 3주로 설정하고 있다(Marx et al., 2003).

$\mathrm{K}-\mathrm{TPFQ}$ 간소화 버전 문항 추출은 TPFQ 간소화 버전 제작 방법과 동일하게 진행하였다(Tyler et al., 2014). Tyler et al. (2014)은 요인 분석 결과를 바탕으로 각 하위척도 내에서 요인
적재량이 높게 나온 문항 중 내용 타당도(content validity)를 고려하여 최종 간소화 버전 문항을 선정하였다. 따라서 본 연 구에서도 각 하위척도마다 높은 요인 적재량을 문항을 확인하 고, 연구자 간 내용 타당도 분석을 통해 총 12 개의 문항을 간소 화 버전의 문항으로 채택하였다. 내용 타당도 분석 시에는 하위 척도 내 구성 문항이 다양한 관점을 확인하고 있는지, 한국어 로 번역된 문항이 한국인이 이해하기 쉬운 내용인지를 중점적 으로 확인하였다. 또한 K-TPFQ 간소화 버전의 신뢰도와 타당 도를 통계적으로 분석하여 설문지의 검증력을 확인하였다.

\section{통계 분석}

본 연구의 결과 분석은 SPSS-version 25 (IBM Corp., Armonk, NY, USA)를 활용하였다. K-TPFQ의 검사-재검사 신 뢰도 검증은 첫 번째 검사 결과와 두 번째 검사 결과의 상관관 계를 피어슨 상관계수를 통해 확인하였다. 또한 요인 분석을 통 하여 $\mathrm{K}-\mathrm{TPFQ}$ 의 타당도 검증을 시행하고자 하였으며, 요인 분 석 결과를 활용하여 간소화 버전의 문항을 추려내고자 하였다. 추려낸 간소화 버전 문항의 내적 일관성을 확인하기 위하여 크 론바흐 알파를 시행하였으며, 간소화 버전의 타당도를 확인하 기 위하여 12 문항의 요인 분석을 시행하여 하위척도별 요인 적 재량을 확인하였다.

\section{RESULTS}

\section{$\mathrm{K}-\mathrm{TPFQ}$ 검사-재검사 신뢰도 측정}

$\mathrm{K}-\mathrm{TPFQ}$ 검사 결과의 평균 점수는 34.4점[standard error $(\mathrm{SE})=3.2$, standard deviation $(\mathrm{SD})=17.9]$ 이었으며, 각 하위척 도의 평균 점수로는 감정 척도가 41.7점 $(\mathrm{SE}=3.7, \mathrm{SD}=20.7)$, 듣 기 능력 척도가 29.6점( $\mathrm{SE}=3.3, \mathrm{SD}=18.4)$, 수면 척도가 35.0 점 $(\mathrm{SE}=4.7, \mathrm{SD}=26.3)$, 집중력 척도가 31.2점 $(\mathrm{SE}=3.1, \mathrm{SD}=$ 17.5)으로 나타났다. 또한 설문지 재검사 결과의 평균 점수는 34.9 점 $(\mathrm{SE}=3.2, \mathrm{SD}=18.0)$ 이었으며, 각 하위척도의 평균 점수 로는 감정 척도가 42.4점 $(\mathrm{SE}=3.7, \mathrm{SD}=20.4)$, 듣기 능력 척도 가 31.8점 $(\mathrm{SE}=3.6, \mathrm{SD}=19.9)$, 수면 척도가 33.0점 $(\mathrm{SE}=4.2$, $\mathrm{SD}=23.2)$, 집중력 척도가 32.6점 $(\mathrm{SE}=3.1, \mathrm{SD}=17.3)$ 으로 나 타났다.

2 3주 간격을 두고 두 번 실시한 K-TPFQ의 응답을 피어슨 상관 분석을 통하여 검사-재검사 신뢰도를 확인하였다. 피어슨 상관계수(r)는 $r<0.3$ 일 경우 무시할 수 있는 상관관계, $0.3 \leq$ $r<0.5$ 일 경우 낮은 양의 상관관계, $0.5 \leq r<0.7$ 일 경우 보 통 정도의 양의 상관관계, $0.7 \leq \mathrm{r}<0.9$ 일 경우 높은 양의 상 관관계, $0.9<\mathrm{r}$ 일 경우 매우 높은 양의 상관관계로 해석할 수 있다(Mukaka, 2012). 본 연구 결과 전체 점수의 검사-재검사 
간 상관계수 값은 0.858 로 높게 나타났다. 각 하위척도별 검사재검사 간 상관계수 값은 감정 하위척도가 0.862 , 듣기 능력 하 위척도가 0.860 , 수면 하위척도가 0.913 , 집중력 하위척도가 0.771 로 높게 나타났다. 각 문항별 점수에 따른 검사-재검사 간 상관계수는 3번 문항 $(\mathrm{r}=0.598)$ 만 보통 정도의 상관관계를 보 였으며 나머지 문항은 모두 높은 상관관계로 나타났다 $(\mathrm{r}=$ 0.723 0.927, $p<0.01$ ) (Table 2).

\section{$\mathrm{K}-\mathrm{TPFQ}$ 간소화 버전 제안}

본 연구에서 시행한 요인 분석에는 문항 수의 5.5 배에 해당 하는 대상자의 응답이 활용되었으며, 이는 요인 분석 시 권장되 는 5 배수를 초과하는 수치였다. $\mathrm{K}-\mathrm{TPFQ}$ 의 요인 분석 결과는 Kaiser-Meyer-Olkin 측도가 0.915였으며, Bartlett의 구형성 검정 근사 카이제곱 값은 $2,550.169(p<0.001)$ 로 $\mathrm{K}-\mathrm{TPFQ}$ 의 모든 문항에서 공통성이 0.4 이상으로 추출되었으며, 따라서 요 인 분석에 적합하였다(Table 3). 모든 문항들의 하위척도 내 요 인 적재량은 0.4 이상으로 적절한 수준을 보였기 때문에 연구 자들의 논의를 통하여 내용 타당도를 고려하여 간소화 버전 12

Table 2. Test-retest reliability of Korean tinnitus primary function questionnaire

\begin{tabular}{|c|c|c|c|}
\hline Variable & Test score & Retest score & Correlation coefficien \\
\hline Emotion & 41.7 & 42.4 & $0.862^{*}$ \\
\hline Item 1 & 46.9 & 52.7 & $0.780^{*}$ \\
\hline Item 4 & 38.4 & 40.6 & $0.915^{*}$ \\
\hline Item 8 & 34.5 & 32.6 & $0.812^{*}$ \\
\hline Item 10 & 39.5 & 39.2 & $0.836^{*}$ \\
\hline Item 12 & 49.4 & 46.8 & $0.846^{*}$ \\
\hline Hearing & 29.6 & 31.8 & $0.860^{*}$ \\
\hline Item 2 & 31.1 & 35.0 & $0.756^{*}$ \\
\hline Item 6 & 30.6 & 31.0 & $0.780^{*}$ \\
\hline Item 9 & 24.8 & 27.1 & $0.775^{*}$ \\
\hline Item 14 & 32.3 & 34.2 & $0.859^{*}$ \\
\hline Item 17 & 29.0 & 31.8 & $0.822^{*}$ \\
\hline Sleep & 35.0 & 33.0 & $0.913^{*}$ \\
\hline Item 5 & 40.2 & 38.4 & $0.885^{*}$ \\
\hline Item 13 & 41.3 & 37.9 & $0.927^{*}$ \\
\hline Item 16 & 32.3 & 31.8 & $0.888^{*}$ \\
\hline Item 18 & 28.1 & 26.1 & $0.854^{*}$ \\
\hline Item 20 & 33.2 & 30.8 & $0.878^{*}$ \\
\hline Concentration & 31.2 & 32.6 & $0.771^{*}$ \\
\hline Item 3 & 21.6 & 26.8 & $0.598^{*}$ \\
\hline Item 7 & 29.6 & 30.6 & $0.799^{*}$ \\
\hline Item 11 & 31.3 & 32.3 & $0.772^{*}$ \\
\hline Item 15 & 35.8 & 36.3 & $0.837^{*}$ \\
\hline Item 19 & 37.7 & 36.9 & $0.723^{*}$ \\
\hline Total & 34.4 & 34.9 & $0.858^{*}$ \\
\hline
\end{tabular}

${ }^{*} p<0.01$
문항을 최종 선정하였다. 본 연구에서 제안한 $\mathrm{K}-\mathrm{TPFQ}$ 간소화 버전 설문 문항은 Appendix에 첨부하였다.

12 문항으로 추려낸 간소화 버전의 신뢰도를 분석하기 위하 여 문항 내적 일관성을 크론바흐 알파를 통해 확인하였다. 일반 적으로 크론바흐 알파 값은 0.7 이상으로 나와야 높은 내적 일 관성을 보였다고 할 수 있는데(Cortina, 1993), 간소화 버전 문 항 전체의 크론바흐 알파 값은 0.934 로 높게 나타났다. 각 하위 척도별 크론바흐 알파 값은 감정 하위척도가 0.928 , 듣기 능력 하위척도가 0.839 , 수면 하위척도가 0.950 , 집중력 하위척도가 0.923으로 나타났다.

간소화 버전의 타당도 분석을 위하여 요인 분석을 실시하였 다. 간소화 버전 문항의 요인 분석 결과는 Kaiser-Meyer-Olkin 측도가 0.876 이었으며, Bartlett의 구형성 검정 근사 카이제곱 값은 $1,319.834(p<0.001)$ 로 $\mathrm{K}-\mathrm{TPFQ}$ 의 모든 문항에서 공통성 이 0.4 이상으로 추출되어 요인 분석에 적합한 수준을 보였다 (Table 4).

\section{DISCUSSIONS}

본 연구는 $\mathrm{K}-\mathrm{TPFQ}$ 의 검사-재검사 신뢰도 및 요인 분석을

Table 3. Result of the factor analysis using the Korean tinnitus primary function questionnaire

\begin{tabular}{|c|c|c|c|c|c|}
\hline \multirow{2}{*}{ Subcategory } & \multirow{2}{*}{ Item } & \multicolumn{4}{|c|}{ Factor loading } \\
\hline & & 1 & 2 & 3 & 4 \\
\hline \multirow[t]{5}{*}{ Sleep } & 5 & 0.881 & & & \\
\hline & 18 & 0.875 & & & \\
\hline & 20 & 0.855 & & & \\
\hline & 16 & 0.828 & & & \\
\hline & 13 & 0.827 & & & \\
\hline \multirow[t]{5}{*}{ Hearing } & 14 & & 0.831 & & \\
\hline & 17 & & 0.828 & & \\
\hline & 2 & & 0.821 & & \\
\hline & 6 & & 0.788 & & \\
\hline & 9 & & 0.710 & & \\
\hline \multirow[t]{5}{*}{ Emotion } & 12 & & & 0.763 & \\
\hline & 8 & & & 0.750 & \\
\hline & 10 & & & 0.722 & \\
\hline & 1 & & & 0.710 & \\
\hline & 4 & & & 0.671 & \\
\hline \multirow[t]{5}{*}{ Concentration } & 11 & & & & 0.789 \\
\hline & 7 & & & & 0.789 \\
\hline & 15 & & & & 0.760 \\
\hline & 3 & & & & 0.702 \\
\hline & 19 & & & & 0.530 \\
\hline Eigen value & & 4.764 & 3.995 & 3.787 & 3.610 \\
\hline Explained variance (\%) & & 23.819 & 19.974 & 18.934 & 18.051 \\
\hline Accumulative variance (\%) & & 23.819 & 43.792 & 62.726 & 80.778 \\
\hline
\end{tabular}


Table 4. Result of the factor analysis using the simplified version of Korean tinnitus primary function questionnaire

\begin{tabular}{lrrrrr}
\hline \multirow{2}{*}{ Subcategory } & Item & \multicolumn{5}{c}{ Factor loading } \\
\cline { 2 - 6 } Sleep & 3 & 0.897 & & & \\
& 12 & 0.850 & & & \\
\multirow{2}{*}{ Emotion } & 11 & 0.818 & & & \\
& 1 & & 0.828 & & \\
Concentration & 5 & & 0.826 & & \\
& 7 & & 0.741 & & \\
Hearing & 8 & & & 0.843 & \\
& 4 & & & 0.805 & \\
& 10 & & & 0.759 & \\
Eigen value & 2 & & & & 0.874 \\
Explained variance (\%) & 9 & & & & 0.799 \\
Accumulative variance (\%) & & 23.494 & 45.110 & 66.545 & 86.138 \\
\hline
\end{tabular}

통한 타당도를 검증하고자 하였다. 또한 요인 분석을 통하여 각 하위척도별로 요인 적재량이 높은 문항들을 추출하여 간소 화 버전을 제안하고, $\mathrm{K}-\mathrm{TPFQ}$ 간소화 버전의 크론바흐 알파 및 요인 분석을 통한 신뢰도 및 타당도를 검증하고자 하였다. $\mathrm{K}-\mathrm{TPFQ}$ 의 검사-재검사 신뢰도 검증 결과 모든 문항에서 상 관관계가 높게 나타나 $(\mathrm{r}=0.598 \sim 0.927, p<0.01)$, 검사-재검사 신뢰도가 높은 것으로 확인되었다. 요인 분석 결과는 KaiserMeyer-Olkin 측도 값이 0.915로 높게 나타나 K-TPFQ의 문항 들이 요인 분석에 적절함을 확인할 수 있었으며, 각 문항의 요 인 적재량은 각 문항이 속한 하위척도에 대하여 모두 높은 수 치를 보였다. 또한 요인 분석 결과에 따라 하위척도별로 높은 요인 적재량을 보인 세 문항을 추려내어, 총 12문항으로 이루어 진 K-TPFQ 간소화 버전을 제안하였다. 간소화 버전의 신뢰도 를 확인하기 위하여 크론바흐 알파로 내적 일관성을 분석한 결 과 높은 내적 일관성을 보였다 $(\alpha=0.934)$. 간소화 버전의 요인 분석 결과 Kaiser-Meyer-Olkin 측도 값이 0.876으로 나타나 추출한 문항들이 요인 분석에 적절함을 확인하였으며, 각 문항 의 요인 적재량 또한 각 문항이 속한 하위척도에 대하여 모두 높은 수치로 나타났다.

본 연구에서 제안한 $\mathrm{K}-\mathrm{TPFQ}$ 간소화 버전은 요인 분석을 이 용한 통계적 근거뿐만 아니라 내용 타당도를 고려하여 문항을 구성하였다. 따라서 요인 분석 결과 요인 적재량이 상대적으로 적게 나타난 문항이더라도 내용 타당도가 높다고 판단될 경우 간소화 버전 문항으로 선정하였다. 간소화 버전을 제안한 선행 연구들의 경우에도 통계적 수치가 낮게 나온 문항이더라도 통 계적으로 검증할 수 없는 내용 타당도 혹은 안면 타당도가 높
다고 판단될 경우 간소화 버전에 문항으로 선정하고, 이를 임 상에 적용하여 사용하고 있다(Hiller \& Goebel, 2004; Newman et al., 2008; Tyler et al., 2014). K-TPFQ 간소화 버전 문 항으로 추출된 문항들을 하위척도별로 확인하면 다음과 같다. 먼저 집중 하위척도의 경우 요인 분석 결과 요인 적재량이 가장 높게 나타난 세 문항이 내용 타당도 측면에서도 적합하다고 판 단되어 간소화 버전 문항으로 선정하였다. 감정 하위척도의 경 우 요인 적재량이 0.763 으로 나타난 12번 문항 "나는 그저 이명 이 사라졌으면 한다. 이명은 좌절감을 크게 안겨준다." 대신 요 인 적재량이 0.710 으로 12 번 문항과 통계적 수치가 큰 차이를 보 이지 않으면서도 문항 내용을 이해하기 쉬워 내용 타당도가 더 적절한 것으로 판단된 1번 문항 “이명 때문에 짜증난다.”를 포함 하였다. 듣기 능력 하위척도의 경우, 요인 적재량이 0.828 로 나 타난 17번 문항 “이명이 나에게 미치는 최악의 영향 중 하나는 청력손실(난청)보다 이명으로 인해 말소리를 듣기 더 어렵다는 점이다." 대신 요인 적재량이 0.710으로 나타나 통계적 수치가 여전히 높으면서도 문항 내용을 이해하기 쉽고, 다양한 관점을 평가할 수 있어 내용 타당도가 더 적절한 것으로 판단된 9번 문 항 “노래와 음악 감상을 방해하는 것은 청력손실 때문이 아니 라 이명 때문이다.”를 포함하였다. 마지막으로 수면 하위척도의 경우, 요인 적재량이 0.875 로 나타난 18 번 문항 “이명 때문에 밤 새 잠을 이루지 못한다.” 대신 요인 적재량이 0.828 로 18 번 문 항과 통계적 수치가 큰 차이를 보이지 않으면서도 다양한 관점 을 평가할 수 있어 내용 타당도가 더 적절한 것으로 판단된 16 번 문항 "이명으로 인한 수면 방해 때문에 하루 종일 피곤함을 느낀다.”를 포함하였다. 또한 이와 같은 방법을 통해 제안된 K$\mathrm{TPFQ}$ 간소화 버전의 내적 일관성을 통한 신뢰도 검증 $(\alpha=$ 0.934) 및 요인 분석을 통한 타당도 검증 결과가 이전 문단에서 서술한 바와 같이 적절한 수준을 보임을 확인할 수 있었다.

본 연구의 결과는 $\mathrm{TPFQ}$ 간소화 버전 개발 및 검증 결과와 유사하게 나타났다(Tyler et al., 2014). 첫 번째로, 간소화 버전 문항 추출 시 $\mathrm{K}-\mathrm{TPFQ}$ 간소화 버전과 $\mathrm{TPFQ}$ 간소화 버전의 집중 하위척도의 구성 문항은 $7,11,15$ 번 문항으로 모두 일치하 였으며, 그 외 하위척도의 구성 문항은 각각 두 문항씩 일치하 였다(감정 하위척도: 8,10 번 문항; 듣기 능력 하위척도: 2, 14번 문항; 수면 하위척도: 16,20 번 문항). 감정 하위척도의 경우 $\mathrm{TPFQ}$ 간소화 버전에서는 4 번 문항 "이명은 마음의 평온을 깨 뜨리는 최악의 요인 중 하나이다."가 포함되었으나, K-TPFQ 간 소화 버전에서는 1 번 문항 “이명 때문에 짜증난다."를 포함하였 다. 듣기 능력 하위척도의 경우 $\mathrm{TPFQ}$ 간소화 버전에서는 17번 문항 “이명이 나에게 미치는 최악의 영향 중 하나는 청력손실 (난청)보다 이명으로 인해 말소리를 듣기 더 어렵다는 점이다.”가 포함되었으나, K-TPFQ 간소화 버전에서는 9번 문항 “노래와 음 
악 감상을 방해하는 것은 청력손실 때문이 아니라 이명 때문이 다."를 포함하였다. 수면 하위척도의 경우 TPFQ 간소화 버전에 서는 18번 문항 “이명 때문에 밤새 잠을 이루지 못한다.”가 포함 되었으나, K-TPFQ 간소화 버전에서는 5 번 문항 "이명 때문에 밤에 잠들기 힘들다."를 포함하였다. 본 연구의 요인 분석 결과 에서 모든 문항의 요인 적재량이 0.4 이상으로 나타나 하위척도 별로 적절한 문항이 구성되어 있다고 볼 수 있다. 따라서 두 간 소화 버전 설문지를 구성하는 문항이 약간의 차이를 보이긴 하 지만, 간소화 설문지의 원래 목적인 문항을 축소시키면서 전체 문항 버전 설문지 검사와 유사한 결과를 얻어야 한다는 것을 염 두에 둔다면 두 간소화 버전 설문지 모두 적절한 문항으로 이 루어졌다고 볼 수 있다(Mun et al., 2013). 두 번째로, TPFQ 간 소화 버전과 K-TPFQ 간소화 버전의 내적 일관성 검증 결과가 유사한 수준으로 나타났다. TPFQ 간소화 버전 전체 문항의 크 론바흐 알파 값은 0.89 로 나타났으며, K-TPFQ 간소화 버전 전 체 문항의 크론바흐 알파 값은 0.93 으로 나타나 유사한 결과를 보였다(Tyler et al., 2014). TPFQ 간소화 버전과 K-TPFQ 간소 화 버전의 각 하위척도별 크론바흐 알파 값을 살펴보면, 감정 하위척도의 경우 각각 $0.90,0.87$, 듣기 능력 하위척도의 경우 각각 $0.90,0.91$, 수면 하위척도의 경우 각각 $0.93,0.95$, 집중력 하위척도의 경우 $0.86,0.92$ 로 나타났다. 따라서 $\mathrm{K}-\mathrm{TPFQ}$ 간소 화 버전의 내적 일관성은 $\mathrm{TPFQ}$ 간소화 버전에 준하는 내적 일 관성을 보였음을 확인할 수 있다.

본 연구는 몇 가지 임상적인 의의를 가진다. Shin et al. (2019)의 K-TPFQ 검증 과정에서 검사-재검사 신뢰도와 요인 분석 검증은 결여되어 있었다. 따라서 $\mathrm{K}-\mathrm{TPFQ}$ 는 본 연구의 추 가적인 검증을 통하여 내적 일관성, 검사-재검사 신뢰도, 구성 타당도, 요인 분석 등의 분석이 완료되어 검증력 및 유용성을 더욱 높일 수 있었다. 특히 본 연구 결과에서 K-TPFQ 간소화 버전의 내적 일관성 $(\alpha=0.87 \sim 0.95)$ 의 신뢰도가 높게 나타났으
며, 요인 분석을 통한 타당도가 적절하게 나타난 것을 확인할 수 있었다. 이러한 결과는 K-TPFQ 간소화 버전이 실제 임상에 적용하기에 무리가 없음을 나타냄과 동시에 다음과 같은 이점 을 시사한다. 20 문항으로 이루어진 $\mathrm{K}-\mathrm{TPFQ}$ 와 12 문항으로 이 루어진 K-TPFQ 간소화 버전의 내적 일관성 분석 결과가 큰 차이가 없었을 뿐만 아니라 두 버전 모두 높은 내적 일관성을 보였다. 따라서 K-TPFQ 간소화 버전의 임상 적용은 설문지 작 성 소요 시간은 절반 정도로 줄이면서 설문지의 검증력 및 타 당성은 유지할 수 있다. 특히 K-TPFQ는 네 가지의 하위척도로 구성되어 있어 하위척도별 점수에 따른 이명 재활 계획을 수립 할 수 있다는 장점이 있는데, 이러한 장점 또한 $\mathrm{K}-\mathrm{TPFQ}$ 간소 화 버전에서도 유지된다.

현재 한국어로 번역된 설문지는 K-THI, Korean version of the THQ (K-THQ), K-TPFQ가 있으며, 이 설문지들의 검증 결 과 및 주요 특징을 Table 5와 같이 비교하여 정리할 수 있다. $\mathrm{K}-\mathrm{THQ}$ 의 경우 내적 일관성 및 수렴 타당도 검증만이 시행되 었으며, 간소화 버전 제안은 이루어지지 않았다. K-TPFQ와 K-THI는 내적 일관성, 검사-재검사 신뢰도, 수렴 타당도, 요인 분석이 모두 이루어졌으며, 간소화 버전 제안 또한 이루어졌다. $\mathrm{K}-\mathrm{TPFQ}$ 는 세 가지 설문지 중 문항 수가 가장 적어 설문지 작 성 소요 시간을 줄일 수 있다는 장점이 있다. 또한 $\mathrm{K}-\mathrm{TPFQ}$ 는 설문지 문항 수가 가장 적음에도 불구하고 통계적 검증 결과가 모두 적절한 값을 보여 이명을 겪고 있는 대상자에게 신속하고 정확한 검사가 가능하여 매우 유용하게 사용될 수 있음을 시 사한다.

본 연구는 다음과 같은 제한점이 있다. $\mathrm{K}-\mathrm{TPFQ}$ 검증 시에는 실시하였던 수렴 타당도 검증을 본 연구의 K-TPFQ 간소화 버 전 검증에서는 실시하지 못하였다. 수렴 타당도 검증의 경우 이 미 검증이 완료된 다른 설문지 검사(Korean version of the Beck depression inventory, Korean version of the Pittsburgh

Table 5. Comparison of characteristics and validation results for three Korean translated tinnitus questionnaires

\begin{tabular}{lccc}
\hline \multicolumn{1}{c}{ Characteristics } & $\begin{array}{c}\text { K-THI } \\
\text { (Kim et al., 2012) }\end{array}$ & $\begin{array}{c}\text { K-THQ } \\
\text { (Jun et al., 2015) }\end{array}$ & $\begin{array}{c}\text { K-TPFQ } \\
\text { (Shin et al., 2019; The present study) }\end{array}$ \\
\hline Subcategory & Functional & Social & Emotion \\
& Emotional & Hearing \\
Catastrophic & Shotional \\
Physical & Concentration \\
Number of items & & 27 & 20 \\
Internal consistency & 25 & $\mathrm{O}(\alpha=0.96)$ & $\mathrm{O}(\alpha=0.93)$ \\
Test-retest reliability & $\mathrm{O}(\alpha=0.95)$ & $\mathrm{X}$ & $\mathrm{O}(\mathrm{r}=0.858)$ \\
Convergent validity & $\mathrm{O}(\mathrm{r}=0.90)$ & $\mathrm{O}$ & $\mathrm{O}$ \\
Factor analysis & $\mathrm{O}$ & $\mathrm{X}$ & $\mathrm{O}$
\end{tabular}

K-THI: Korean version of the tinnitus handicap index, K-THQ: Korean version of the tinnitus handicap questionnaire, K-TPFQ: Korean version of the tinnitus primary function questionnaire 
sleep quality index, Korean version of the state-trait anxiety inventory, $\mathrm{K}-\mathrm{THQ})$ 와 병행하여 실시되어야 하고, 이 과정에서 소요되는 시간적 한계 때문에 본 연구에서는 검증을 실시하지 못하였다. 향후 연구를 통하여 K-TPFQ 간소화 버전의 수렴 타 당도 검증이 이루어진다면 각 하위척도별 구성 개념이 적절히 이 루어졌는지 확인할 수 있어 설문지의 검증력을 더욱 높일 수 있 을 것이다.

$\mathrm{K}-\mathrm{TPFQ}$ 는 기존에 한국어로 번역된 다른 이명 설문지와 비 교하여 몇 가지 이점을 가지고 있다. K-TPFQ는 이명이 업무나 일상생활 등에 영향을 주는 주요한 일차적인 영향 네 가지를 하위척도로 평가하며, 이를 통하여 상담을 효과적으로 진행할 수 있을 뿐만 아니라 높은 점수가 나온 하위척도가 있다면 그 부분에 초점을 맞추어 재활 계획을 구체적으로 수립할 수 있 다. 또한 $\mathrm{K}-\mathrm{TPFQ}$ 의 전체 문항 수(20문항)는 $\mathrm{K}-\mathrm{THI}(25$ 문항), $\mathrm{K}-\mathrm{THQ}$ (27문항)보다 더 적게 이루어져 있어 소요 시간이 단축 되는 장점이 있다. 본 연구에서 제안한 K-TPFQ 간소화 버전의 경우 또한 소요 시간을 단축시킬 수 있는 방법으로 바쁜 임상 에서 유용하게 사용될 수 있으며, 연구 환경에서도 연구 대상 자를 빠르게 선별할 수 있는 수단으로 사용 가능할 것이다.

이명 설문지는 주관적 이명을 간접적으로 평가할 수 있는 심 리학적 방법으로써 이명 재활 및 치료에 중요한 역할을 한다. 따라서 이명 설문지의 검증 또한 매우 중요한데, $\mathrm{K}-\mathrm{TPFQ}$ 는 Shin et al.(2019)의 연구와 본 연구를 통하여 내적 일관성, 수 렴 타당도, 검사-재검사 신뢰도 및 요인 분석 등의 검증 과정에 서 높은 신뢰도와 타당도를 보여주었으며, 간소화 버전을 통한 설문지 작성 소요 시간 단축이 가능하므로 국내 임상에서 유 용한 이명 설문지로써 활용할 수 있을 것이다.

중심 단어 : 이명·이명주요기능설문지·설문지·신뢰도·요인 분석.

\section{Ethical Statement}

The study was approved by the Institutional Review Board of Hallym University (HIRB-2019-002-1-R).

\section{Acknowledgments} N/A

\section{Declaration of Conflicting Interests}

There are no conflict of interests.

\section{Funding}

This work has supported by the National Research Foundation of Korea (NRF) grant funded by the Korea government (MSIT) (NRF-2018 R1C1B6003765).

\section{Author Contributions}

All authors contributed equally to this work. S.H. and I.J. designed and performed experiments, analyzed data, and wrote the paper; S.H. and I.J. provided statistical analysis and critical revision; S.H. and I.J. designed experiments, analyzed data, and wrote the paper. Also, the authors discussed the results together and implications and commented on the manuscript at each stage.

\section{ORCID iDs \\ Sohee Heo \\ In-Ki Jin \\ https://orcid.org/0000-0001-8339-1139 \\ https://orcid.org/0000-0002-0834-5981}

\section{REFERENCES}

Choi, C. H. (2012). Psychometric and psychoacoustic measures of tinnitus. Audiology, 8(2), 137-148.

Cortina, J. M. (1993). What is coefficient alpha? An examination of theory and applications. Journal of Applied Psychology, 78(1), 98-104.

de Yébenes Prous, M. J. G., Salvanés, F. R., \& Ortells, L. C. (2009). Validation of questionnaires. Reumatología Clínica (English Edition), 5(4), 171-177.

Hall, D. A., Zaragoza Domingo, S., Hamdache, L. Z., Manchaiah, V., Thammaiah, S., Evans, C., et al.; International Collegium of Rehabilitative Audiology and Tinnitus Research NETwork. (2018). A good practice guide for translating and adapting hearing-related questionnaires for different languages and cultures. International Journal of Audiology, 57(3), 161-175.

Harkness, J., Pennell, B. E., \& Schoua-Glusberg, A. (2004). Survey questionnaire translation and assessment. In Presser, S., Rothgeb, J. M., Couper, M. P., Lessler, J. T., Martin, E., Martin, J., et al. Methods for Testing and Evaluating Survey Questionnaires (pp. 453-473). Hoboken, NJ: John Wiley \& Sons, Inc.

Heller, A. J. (2003). Classification and epidemiology of tinnitus. Otolaryngologic Clinics of North America, 36(2), 239-248.

Henry, J. A., Schechter, M. A., Zaugg, T. L., Griest, S., Jastreboff, P. J., Vernon, J. A., et al. (2006). Clinical trial to compare tinnitus masking and tinnitus retraining therapy. Acta Oto-Laryngologica. Supplementum, 126(sup556), 64-69.

Hiller, W. \& Goebel, G. (2004). Rapid assessment of tinnitus-related psychological distress using the Mini-TQ. International Journal of Audiology, 43(10), 600-604.

Jastreboff, P. J. (1990). Phantom auditory perception (tinnitus): Mechanisms of generation and perception. Neuroscience Research, 8(4), 221254.

Jastreboff, P. J. \& Jastreboff, M M. (2000). Tinnitus Retraining Therapy (TRT) as a method for treatment of tinnitus and hyperacusis patients. Journal of the American Academy of Audiology, 11(3), 162-177.

Jun, H. J., Yoo, I. W., Hwang, S. J., \& Hwang, S. Y. (2015). Validation of a Korean version of the tinnitus handicap questionnaire. Clinical and Experimental Otorhinolaryngology, 8(3), 198-201.

Kim, J. H., Lee, S. Y., Kim, C. H., Lim, S. L., Shin, J. N., Chung, W. H., et al. (2002). Reliability and validity of a Korean adaptation of the tinnitus handicap inventory. Korean Journal of Otorhinolaryngology-Head and Neck Surgery, 45(4), 328-334.

Kuk, F. K., Tyler, R. S., Russell, D., \& Jordan, H. (1990). The psychometric properties of a tinnitus handicap questionnaire. Ear and Hearing, 11(6), 434-445.

Lanting, C. P., de Kleine, E., \& van Dijk, P. (2009). Neural activity underlying tinnitus generation: Results from PET and fMRI. Hearing Research, 255(1-2), 1-13

Lee, J., Lee, K., Oh, H., Jeong, S., \& Jin, I. K. (2018). Analytical review of tinnitus questionnaires: Characteristics and understanding. Audiology and Speech Research, 14(2), 73-80.

Malouff, J. M., Schutte, N. S., \& Zucker, L. A. (2011). Tinnitus-related distress: A review of recent findings. Current Psychiatry Reports, 13(1), 3136.

Marx, R. G., Menezes, A., Horovitz, L., Jones, E. C., \& Warren, R. F. (2003). 
A comparison of two time intervals for test-retest reliability of health status instruments. Journal of Clinical Epidemiology, 56(8), 730-735.

McFadden, D. (1982). Tinnitus: Facts, Theories, and Treatment. (pp. 120122). Washington, DC: The National Academies Press.

Meikle, M. B., Henry, J. A., Griest, S. E., Stewart, B. J., Abrams, H. B., McArdle, R., et al. (2012). The tinnitus functional index: Development of a new clinical measure for chronic, intrusive tinnitus. Ear and Hearing, 33(2), 153-176.

Mukaka, M. M. (2012). Statistics corner: A guide to appropriate use of correlation coefficient in medical research. Malawi Medical Journal, 24(3), 69-71.

Mun, M. J., Goh, E. K., Oh, S. J., Kwon, H. K., Kong, S. K., \& Lee, I. W. (2013). Development of simplified version of Korean-type tinnitus handicap inventory. Korean Journal of Otorhinolaryngology-Head and Neck Surgery, 56(3), 138-143.

Nam, E. C. \& Ryu, Y. J. (2018). A case of pulsatile tinnitus caused by idiopathic intracranial hypertension in the female obese patient. Audiology and Speech Research, 14(1), 55-58.

Newman, C. W., Jacobson, G. P., \& Spitzer, J. B. (1996). Development of the tinnitus handicap inventory. Archives of Otorhinolaryngology-Head and Neck Surgery, 122(2), 143-148.

Newman, C. W., Sandridge, S. A., \& Bolek, L. (2008). Development and psychometric adequacy of the screening version of the tinnitus handicap inventory. Otology and Neurotology, 29(3), 276-281.

Reavis, K. M., Rothholtz, V. S., Tang, Q., Carroll, J. A., Djalilian, H., \& Zeng, F. G. (2012). Temporary suppression of tinnitus by modulated sounds. Journal of the Association for Research in Otolaryngology, 13(4), 561571.

Schmidt, M. E. \& Steindorf, K. (2006). Statistical methods for the validation of questionnaires--discrepancy between theory and practice. Methods of Information in Medicine, 45(4), 409-413.

Shin, J., Heo, S., Lee, H. K., Tyler, R., \& Jin, I. K. (2019). Reliability and validity of a Korean version of the tinnitus primary function questionnaire. American Journal of Audiology, 28(2), 362-368.

Tyler, R., Ji, H., Perreau, A., Witt, S., Noble, W., \& Coelho, C. (2014). Development and validation of the tinnitus primary function questionnaire. American Journal of Audiology, 23(3), 260-272.

World Health Organization. (2001). International Classification of Functioning, Disability and Health: ICF. (pp. 3-4). Geneva: World Health Organization. 


\section{APPENDIX}

Simplified Version of the Korean Tinnitus Primary Function Questionnaire (S-K-TPFQ)

각 설문지에 대해 ‘전혀 그렇지 않다’는 0점으로, '매우 그렇다’는 100점으로, 그 중간은 0에서 100점 사이 점수로 표시해 주십시오.

\begin{tabular}{|c|c|c|}
\hline Number & Item & Score \\
\hline 1 & 이명 때문에 짜증난다. & \\
\hline 2 & 이명 때문에 잘 들리지 않는 말소리가 있다. & \\
\hline 3 & 이명 때문에 밤에 잠들기 힘들다. & \\
\hline 4 & 이명 때문에 내 업무에 집중하는 것이 어렵다고 느낀다. & \\
\hline 5 & 나는 이명 때문에 우울하다. & \\
\hline 6 & 노래와 음악 감상을 방해하는 것은 청력손실 때문이 아니라 이명 때문이다. & \\
\hline 7 & 나는 이명 때문에 괴롭다. & \\
\hline 8 & 이명으로 인해 중요한 일들에 주의를 집중하기 어렵다. & \\
\hline 9 & 청력손실과 더불어 이명은 말소리를 이해하기 어렵게 방해한다. & \\
\hline 10 & 이명이 나에게 미치는 최악의 영향 중 하나는 이명으로 인해 생각에 집중하지 못한다는 점이다. & \\
\hline 11 & 이명으로 인한 수면 방해 때문에 하루 종일 피곤함을 느낀다. & \\
\hline 12 & 밤중에 잠에서 깼을 때, 이명 때문에 다시 잠을 이루기가 힘들다. & \\
\hline
\end{tabular}

